DANSON, C., \& CREED, T. Rate of response as a visual social stimulus. Journal of the Experimental Analysis of Behavior, $1970,13,233-242$

DARBY, C. L., \& RIOPELLE, A. J. Observational learning in the rhesus monkey. Journal of Comparative \& Physiological Psychology, 1959, 52. 94-97.

GEWIRTZ，J. H., \& STINGLE, K. G. Learning of generalized imitation as the basis for identification. Psychological
Review, 1968, 75, 374-396.

KIMBLE G. A Hilgard \& Marquis Conditioning and learning. (Rev. ed.) New York: Appleton-Century-Crofts, 1961.

LOVAAS, O. I., BERBERICH, B. F., \& PERLOFF, B. F Acquisition of imitative speech by schizophrenic children. Science, 1966, 151, 705-707.

PETERSON, R. F. Some experiments on the organization of a class of imitative behaviors. Journal of Applied Behavior Analysis, 1968, 1, 225-235.

\section{Differential resistance to extinction as a function of fixed-interval contrast in training*}

\author{
MELVIN H. MARX and DAVID W. WITTER \\ University of Missouri, Columbia, Mo. 65201
}

Differential fixed-interval schedules were used to test the previously advanced motivational theorv of extinction, which predicts positive or negative contrast effects in extinction as a function of acquisition experience. Rats trained on both FI 10-sec and FI 40-sec schedules of bar presentation and extinguished on FI $10 \mathrm{sec}$ (all within a discrete-trial experimental design) were significantly more resistant to extinction than were control Ss both trained and extinguished on FI 10 sec. On the other hand, rats receiving mixed training and extinguished on FI $40 \mathrm{sec}$ were significantly less resistant to extinction than were control Ss trained and extinguished on FI $40 \mathrm{sec}$. These findings are interpreted as lending additional support to the motivational theory of extinction.

This experiment was performed to test a prediction derived from the motivational theory of extinction advanced earlier (Marx, 1966). A number of experiments were performed with animals whose training was administered under two contrasting conditions, one more "preferred" than the other (e.g., FR 1 and FR 5, 0-sec and 20 -sec delay in goalbox). These animals were then extinguished in either the preferred or the nonpreferred condition and compared in each case with controls that had been trained only under that condition. The rationale for tho prediction of superior performance for the animals tested under the preferred condition (a form of positive contrast) and inferior performance for those

*This research was supported in part by Grants GB5853 and GB8506 from the National Science Foundation and by Research Career Award 1-K-6-MH 22023 to the first author from the National Institute of Mental Health. tested under the nonpreferred condition (a form of negative contrast) was that the contrast with the other training condition diminished the effect of extinction in the first case and enhanced it in the second. The resulting alteration in the animal's motivation to make the instrumental response would then reflect either a positive contrast effect in extinction (PCEE) or a negative contrast effect in extinction (NCEE). This prediction was generally supported in the various experiments.

The present experiment extends this experimental design to training under fixed-interval reinforcement conditions, applied within a discrete-trial (controlled-operant) framework. An important advantage of the FI schedule for the present purpose is that it provides two especially sensitive measures of motivation-the number of instrumental responses emitted during the interval before reinforcement, as well as the latency of the first response. However, because of the deviation from orthodox Skinnerian usage, the meaning of the term "FI schedule" within the present experimental context must be clearly stated. This term here refers solely to the program of bar presentation and retraction and to the relationship of barpresses and consequent magazine operations to that program. In training, magazine operations produced by barpresses within the period of bar presentation provided food (reinforcement), whereas, in extinction, barpresses operated the magazine in exactly the same manner but produced no food (empty magazines). Thus, the training and extinction schedules of bar presentation and magazine operation were identical, the only difference being the absence of food in the latter phase.

In this experiment it was predicted that rats trained under both FI 40 -sec and FI $10-\mathrm{sec}$ conditions would extinguish more rapidly when tested on the less preferred FI 40-sec schedule, as compared with rats trained and tested only on that schedule. Similarly, such rats were predicted to extinguish more slowly when tested under the FI 10-sec conditions and compared with the appropriate controls (FI 10-sec training and testing).

\section{SUBJECTS}

The Ss were 40 young ( 3 months) and experimentally naive female hooded rats from the Long-Evans strain maintained by the Department of Psychology. Three Ss were lost during the course of the experiment from death or failure to train, leaving two groups with $10 \mathrm{Ss}$ each, one with 9 , and one with 8 .

\section{APPARATUS}

The controlled operant conditioning boxes used have been described in detail previously (Marx, Tombaugh, Hatch, \& Tombaugh, 1965). For this experiment they were operated by, and the data were recorded by, a Honeywell DDP-116 computer. Two retractable bars with associated food magazines were used in each of the eight boxes.

\section{EXPERIMENTAL DESIGN}

The design was a 2 by 2 factorial, with two discrete-trial training conditions (experimental Ss trained on both FI 10 -sec and FI 40-sec schedules, control Ss trained on either FI 10-sec or FI 40-sec schedules), and two extinction conditions (FI $10-\mathrm{sec}$ or FI 40-sec schedules).

\section{PROCEDURE}

The Ss were maintained for 1 week on a reduced feeding program to lower their body weights to $85 \%$ of the ad lib level. Thereafter, they were given a maximum of $10 \mathrm{~g}$ daily of 
Purina mash, adjusted in accordance with their current weight to maintain it at the $85 \%$ level. Each reinforcement throughout training was $.10 \mathrm{~m}$ of $32 \%$ sucrose solution. For magazine training, 3 days with 20 trials per day were given on the right side and 1 day with 20 trials on the left side. The magazines were operated in a random sequence, at 30 -sec intervals, within each run for 5 additional days.

The right bar was presented for 20 trials on the first day of barpress training, and on the second day the left bar was presented for 20 trials. A total of 22 days of further training on both bars, 6 trials on each per session, was then administered.

A total of $17 \mathrm{FI}$ training days, to asymptotic mean latencies, followed. In this training procedure the basic bar presentation and retraction program, called $\mathrm{CI}$ (for controlled interval), was combined with the FI 10-sec and FI 40 -sec schedules. The resulting discrete-trial program is called CI(FI) to indicate the incorporation of the FI schedule within the larger (CI) period of bar presentation (the trial). Thus, the initial training program for half of the rats was CI $70(\mathrm{FI} 40) / 30$, indicating that on each trial the bar appeared for a maximum time of $70 \mathrm{sec}$, or until pressed after the completion of the first $40 \mathrm{sec}$, and that the intertrial interval (time between either effective bar pressing or automatic retraction of bar at end of CI) was $30 \mathrm{sec}$ (indicated by /30 at the end of the notation). The other half of the Ss were trained initially on CI 40 (FI10)/30. After 4 such training days, the CI was reduced by 10 sec for all $\mathrm{Ss}$ for 2 days, and thereafter, by an additional $10 \mathrm{sec}$. The intertrial interval was $30 \mathrm{sec}$ throughout the experiment.

Six days of extinction were then given, with 40 trials per day on CI 20 (FI10)/30 or CI 50 (FI40) 130 -sec schedules.

In acquisition, the control groups (C10 and $\mathrm{C} 40$ ) were trained on both bars, presented in a random order, under the same presentation schedule. The experimental groups (E10 and $\mathrm{E} 40$; the number indicates the extinction condition) were trained on one bar at FI $10 \mathrm{sec}$ and the other bar at FI 40 sec. For the FI $10-\mathrm{sec}$ condition, half of these Ss had the left bar and half the right bar.

In extinction, the control groups were extinguished on only one of the two training bars. Half of each group was tested on each bar, randomly determined. Groups E10 and E 40 were each composed of equal numbers of rats from the two training groups (right bar or left bar for the test value), with the decision for individual Ss again being randomly determined.

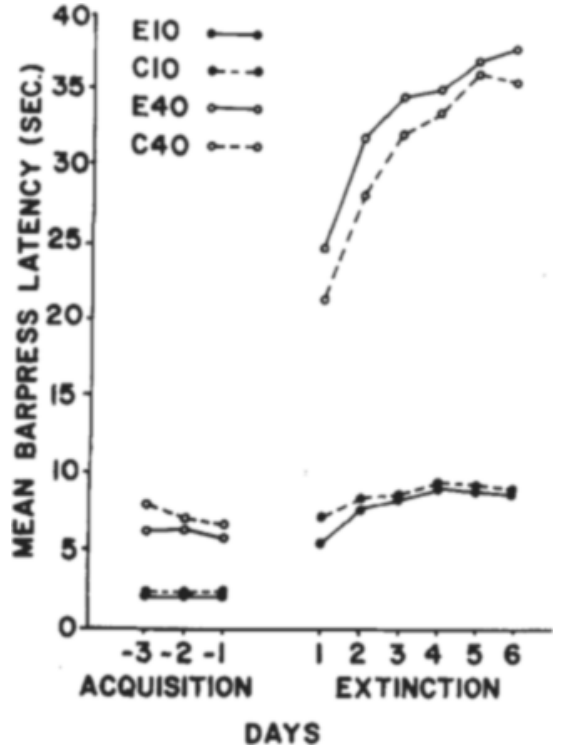

Fig. 1. Mean latencies for last 3 days of acquisition and 6 days of extinction.

\section{RESULTS}

Figure 1 shows the major results in acquisition and extinction using mean response latencies (time to barpress during each controlled interval). Acquisition data for experimental Ss are for the FI on which each $S$ was subsequently extinguished. Neither of the acquisition comparisons (between 10 -sec groups and between 40-sec groups) showed significant differences (both ps $>.05$ by an analysis of variance), nor was there an interaction over the 3 acquisition days for either comparison.

Both of the predicted extinction results appear to have occurred, with Group E10 showing faster responses in extinction than Group C10, thus indicating a PCEE; this result is especially impressive in view of the negligible differences during terminal acquisition trials. Group $\mathrm{E} 40$, on the other hand, appears to have responded more slowly than Group $\mathrm{C} 40$ during extinction, even though the opposite (but nonreliable) relationship was present during acquisition; this difference represents a NCEE. Testing of these differences by analysis of variance supported the conclusions mentioned. Both of the extinction comparisons showed reliable differences at beyond the .05 level of significance $(F=5.29, \mathrm{df}=1 / 18$ for the E10/C10 comparison, and $\mathrm{F}=5.04, \mathrm{df}=1 / 15$ for the $\mathrm{E} 40 / \mathrm{C} 40$ comparison).

The results for number of barpresses were comparable to those for latency; Group E10 produced a mean of 1.01 barpresses/trial, as against .72 for
Group $\mathrm{C} 10$, again indicating a PCEE. This difference was reliable at the .05 level by an exact probability test $(\mathrm{F}=4.36, \quad \mathrm{df}=1 / 18, \quad \mathrm{p}=.0488)$. Group E40 produced a mean total of 1.23 barpresses/trial, compared with 1.43 for Group C40; this difference, however, was not statistically reliable $(F<1)$. Neither of the acquisition curves differed reliably on this measure (both ps $>.05$ ).

\section{DISCUSSION}

The major theoretical import of the present PCEE and NCEE is that they extend the generality of the extinction effects earlier reported by Marx (1966) and thereby lend support to the motivational interpretation of extinction that was then advanced. According to this view, S's motivation to perform an instrumental response is the critical determiner of the expression of that response in extinction; the process of extinction occurs because of a significant progressive decrement in this instrumental motivation. Any variables that affect the course of this decline, such as the contrast effects postulated for the experimental $S s$ in the present design, will have a corresponding influence on extinction.

Apart from these theoretical matters, the present data may be more generally interpreted as providing empirical support for both kinds of contrast effects. The evidence is especially clear for the PCEE since statistically reliable differences occurred with both of the dependent variables used. The statistically reliable difference in latency also gives support to a NCEE, even though the barpress difference was not great enough for statistical reliability. This clearer expression of a positive contrast effect is especially noteworthy in view of the overall results reported for acquisition, where the negative effect is common but the positive effect is difficult to obtain (cf. Dunham, 1968; Black, 1968; Marx, 1969).

\section{REFERENCES}

BLACK, R. W. Shifts in magnitude of reward and contrast effects in instrumental and selective learning: $A$ reinterpretation. Psychological Review, $1968,78,114-126$.

DUNHAM, P. J. Contrasted conditions of reinforcement: A selective critique. Psychological Bulletin, 1968, 69, 295-315.

MARX, M. H. The activation of habits. Psychological Reports, 1966, 19. 527-550.

MARX, M. H. Positive contrast in instumental learning from qualitative shift in incentive. Psychonomic Science, 1969, 16, 254-255.

MARX, M. H., TOMBAUGH, T. N. HATCH, R. S., \& TOMBAUGH, J. W. Controlled operant conditioning boxes with discrete-trial programming for multiple experimental use. Perceptual \& Motor Skills, 1965, 21, 247-254. 